\title{
The Application of Multinomial Logistic Regression Models for the Assessment of Parameters of Oocytes and Embryos Quality in Predicting Pregnancy and Miscarriage
}

\author{
Anna Justyna Milewska ${ }^{1}$, Dorota Jankowska ${ }^{1}$, Teresa Więsak ${ }^{2}$, \\ Brian Acacio ${ }^{3}$, Robert Milewski ${ }^{1}$ \\ ${ }^{1}$ Deartment of Statistics and Medical Informatics, Medical University of Bialystok, \\ Poland \\ 2 Department of Gamete and Embryo Biology, Institute of Animal Reproduction and \\ Food Research of Polish Academy of Sciences in Olsztyn, Poland \\ 3 Acacio Fertility Center, Laguna Niguel, California, USA
}

\begin{abstract}
Infertility is a huge problem nowadays, not only from the medical but also from the social point of view. A key step to improve treatment outcomes is the possibility of effective prediction of treatment result. In a situation when a phenomenon with more than 2 states needs to be explained, e.g. pregnancy, miscarriage, non-pregnancy, the use of multinomial logistic regression is a good solution. The aim of this paper is to select those features that have a significant impact on achieving clinical pregnancy as well as those that determine the occurrence of spontaneous miscarriage (non-pregnancy was set as the reference category). Two multi-factor models were obtained, used in predicting infertility treatment outcomes. One of the models enabled to conclude that the number of follicles and the percentage of retrieved mature oocytes have a significant impact when prediction of treatment outcome is made on the basis of information about oocytes. The other model, built on the basis of information about embryos, showed the significance of the number of fertilized oocytes, the percentage of at least 7 -cell embryos on day 3 , the percentage of blasts on day 5 , and the day of transfer.
\end{abstract}

\section{Introduction}

Infertility is a huge problem nowadays, not only medical, but also psychological, demographic, and social. In many cases, the only effective method of treatment of infertile couples is assisted reproductive technology (ART) (Radwan \& Wołczyński, 2011). Despite the intensive improvement of the techniques made in recent years, the effectiveness of treatment is still lower than expected, remaining at above $40 \%$ (Milewski et al., 2013) and depending on numerous factors (e.g. female age, but also the type of 
stimulation, duration of culturing, among others). A key step to improve treatment outcomes is the possibility of effective prediction of the result of treatment. When treatment outcome can be effectively predicted on the basis of the available information, it becomes possible to adjust selected parameters of treatment in such a way as to improve treatment outcomes.

The use of advanced data analysis methods such as data mining or artificial intelligence algorithms for the prediction of infertility treatment results has become popular recently (Milewska et al., 2011, 2014, 2016; Milewski et al., 2016). However, basic regression modelling is still being successfully applied. When creating models predicting the effectiveness of infertility treatment, binary phenomena (pregnancy - non-pregnancy; birth of a healthy child - no birth, etc.) are treated as dependent variables. While the logistic regression method is used for modelling such phenomena (Yildirim et al., 2017), there are situations in which one deals with phenomena with more than 2 states. In order to use the standard logistic regression method, the multi-state variable would have to be divided into several binary variables to be modelled separately. Nonetheless, this is not an adequate solution, thus it would be more beneficial to create a single model that could deal with more than one binary dependent variable. Using multinomial logistic regression seems to be an appropriate solution in this situation (Atkinson et al., 2016; Mukesi et al., 2017; Pesatori et al., 2013). For reasons that are difficult to fathom, this method is quite rarely used in Poland, therefore it needs popularization, resulting in this article.

\section{Multinomial Logistic Regression Model}

Logistic regression is a statistical method used to estimate the probability of occurrence of a binary outcome based on a set of explanatory features. It allows to describe the influence of the considered factors on the analysed dichotomous variable. On the other hand, if the dependent variable has at least 3 unordered categories, then multinomial logistic regression (MLR) should be used. The MLR method was created on the basis of the concepts of binomial logistic regression and has the same basic setup, thus it can be said that it is an extension of logistic regression (Hosmer \& Lemeshow, 2000). Multinomial logistic regression is also known as the polytomous or multiclass logistic regression method.

Let us assume that we consider $K$ predictors $X_{1}, X_{2}, X_{3}, \ldots, X_{K}$ (they may be continuous and/or categorical) and outcome variable $Y$ with $J$ nom- 
inal categories. Then the multinomial logistic regression model may be presented as:

$$
\operatorname{logit}\left(Y_{j}\right)=\ln \left[\frac{P(Y=j \mid \boldsymbol{X})}{P(Y=J \mid \boldsymbol{X})}\right]=\beta_{j 0}+\beta_{j 1} X_{1}+\beta_{j 2} X_{2}+\ldots+\beta_{j K} X_{K}
$$

where $j=1,2, \ldots, J-1$. In such a way, we have $J-1$ logit equations. Each of them is a linear function that models the logarithm of probability as having response $j$ to baseline category $J$ (Agresti, 2002). All logits are defined relative to such a predetermined baseline category. It is important to point out that, because they are unordered, any of the $J$ categories can be taken as the reference outcome (El-Habil, 2012). Logit coefficient $\left(\beta_{j k}\right)$ provides information on how great a change in the logit is made by a oneunit increase of the value of $k$-th predictor (while the values of the other variables remain unchanged). The relative risk ratio (RRR) is used the most commonly for the interpretation of the model:

$$
\frac{P(Y=j \mid \boldsymbol{X})}{P(Y=J \mid \boldsymbol{X})}=\exp \left(\beta_{j 0}+\sum_{k=1}^{K} \beta_{j k} X_{K}\right)
$$

RRR is an exponential function of regression coefficients. RRR greater than 1 means that the probability of occurrence of $j$-th category is greater than the probability of obtaining reference category $J$. Due to the fact that the sum of all probabilities $P(Y=j \mid \boldsymbol{X})$, where $j=1,2, \ldots, J$, equals one, it is easy to establish that:

$$
\begin{aligned}
& P(Y=j \mid \boldsymbol{X})=\frac{\exp \left(\beta_{j 0}+\beta_{j 1} X_{1}+\beta_{j 2} X_{2}+\ldots+\beta_{j K} X_{K}\right)}{1+\sum_{j=1}^{J-1} \exp \left(\beta_{j 0}+\beta_{j 1} X_{1}+\beta_{j 2} X_{2}+\ldots+\beta_{j K} X_{K}\right)} \\
& P(Y=J \mid \boldsymbol{X})=\frac{1}{1+\sum_{j=1}^{J-1} \exp \left(\beta_{j 0}+\beta_{j 1} X_{1}+\beta_{j 2} X_{2}+\ldots+\beta_{j K} X_{K}\right)}
\end{aligned}
$$

Parameters $\beta_{j k}(j=1,2, \ldots, J ; k=1,2, \ldots, K)$ are estimated using the maximum likelihood method (Hosmer \& Lemeshow, 2000; Tabatabai et al., 2014). The likelihood function for $n$ independent observations can be written as:

$$
L(\beta)=\prod_{i=1}^{n} \prod_{j=1}^{J} P(Y=j)^{d_{i j}}
$$

where

$$
d_{i j}= \begin{cases}1 & \text { if } Y_{i}=j \\ 0 & \text { if } Y_{i} \neq j\end{cases}
$$


so $d_{i j}=1$ if $i$-th case belongs to $j$-th category. It is possible to determine the parameters of a multinomial logistic regression model in several steps. It is necessary to take the logarithm of such a function $L(\beta)$ and calculate the first partial derivatives of $\ln L(\beta)$ with respect to each of the estimated $\beta_{j k}$ coefficients. Then these equations should be set to 0 and solved.

The testing of statistical significance of individual regression coefficients $\left(\beta_{k}\right)$ is performed with the use of test statistics based on the Wald coefficient:

$$
\operatorname{Wald}(Z)=\frac{\beta_{k}}{S E(\beta)} .
$$

In order to confirm the appropriateness of the whole model created with the use of the MLR method, the likelihood ratio chi-square test must be performed. Test statistics is based on the difference of logarithms of the likelihood function of the reduced model with intercept only $\left(L_{0}\right)$ and the fitted final model $\left(L_{1}\right)$, in which $p=K \cdot(J-1)$ parameters are considered:

$$
L R=-2\left(\ln L_{0}-\ln L_{1}\right) \sim \chi_{p}^{2}
$$

The multinomial logistic regression model is used to describe a qualitative, nominal and multicategorical dependent variable. This solution allows to estimate the probability of occurrence of one of the different possible outcomes on the basis of independent characteristics, which may be of any type: continuous, nominal or ordinal. It can be useful to solve classification problems. It also enables the identification of factors that affect the dependent variable. The prepared model gives the possibility to explain, in terms of relative risk ratio, how strong this impact is.

\section{Applications in Medicine}

All of the aforementioned aspects result in the method being widely used. For this reason, publications can be found in which the multinomial logistic regression model is applicable in areas as diverse as banking, for the assessment of credit risk (Miyamoto, 2014; Van Deventer et al., 2013), or tourism - to describe variables that influence choices concerning travel made by tourists (Can, 2013). The method proved successful for the determination of socioeconomic factors that affect major choices made by consumers when purchasing food (Kohansal \& Firoozzare, 2013). Another example of 
the use of this type of model was the search for the most important risk factors of violence against woman in Palestinian society, among the various socioeconomic, demographic, political, and cultural characteristics as well as variables related to education, housing conditions, or describing the partner (Okasha \& Abu-Saada, 2014).

Multinomial logistic regression is often used in different branches of medicine. There are numerous publications applying this method in allergology. For instance, Mukesi et al. (2017) found out the most common causes of several types of skin allergies while Ranciere et al. (2013) studied the associations between dry night cough, atopy and allergic morbidity. A method that applies MLR models also proves to be effective in oncology. As an example, Pesatori et al. (2013) investigated the association between oral contraceptive use, hormone replacement therapy, and lung cancer risk in women. Atkinson et al. (2016), on the other hand, confirmed that being overweight or obese, age at first pregnancy greater than 26, breastfeeding, and smoking should be considered as important risk factors for Inflammatory Breast Cancer of different subtypes. Furthermore, some works show that MLR can be useful in explaining processes occurring in areas of medicine such as genetics (Cleynen et al., 2016), cardiology (Dolansky et al., 2010), or stomatology (Medina-Solis et al., 2008).

Researchers conducting studies in the area of gynaecology and obstetrics also frequently reach for MLR-based models, which enabled, among others, to indicate factors associated with excess and inadequate weight gain during pregnancy (Neupane et al., 2015). In addition, authors of publications compared the results of analyses with models created with the use of the separate binomial logistic regressions approach. Al-balushi et al. (2016), in a publication entitled "Contraceptive Method Choices Among Women In Oman: A Multilevel Analysis", showed the advantage of the multinomial logistic regression model over the separate binomial logistic regression model, if the analysed variable takes multiple categories. It was noticed that the effects of predictors on different groups of the explained variable can be estimated simultaneously and tested for equivalence in a multilevel model. Al-balushi et al. (2016) investigated the socio-economic, demographic, and individual characteristics that have influence on the decision to choose and use a particular method of contraception, traditional or modern, among women in Oman. Sadat-Hashemi et al. (2005), on the other hand, prepared models predicting the type of pregnancy, i.e. wanted, unwanted by wife, unwanted by husband, or unwanted by the couple, with the use of MLR. The obtained results were compared with the classifier created on the basis of a neural network. 


\section{Assessment of Parameters of Oocytes and Embryos Quality in Predicting Pregnancy and Miscarriage}

The aim of this paper was to select the features that have a significant impact on achieving clinical pregnancy and those that determine the occurrence of spontaneous miscarriage. Three questions were asked:

1. Is it possible to predict the probability of achieving pregnancy or miscarriage on the basis of information about the number and quality of oocytes retrieved from the woman?

2. Is it possible to predict the probability of achieving pregnancy or miscarriage on the basis of information about the number and quality of the produced embryos?

3. Is it possible to predict the probability of achieving pregnancy or miscarriage on the basis of information about the quality of both oocytes and embryos?

During the statistical analysis, multinomial logistic regression (MLR) models were built; STATA 12.0 was used for this purpose. Kruskal-Wallis test with post-hoc multiple mean rank comparisons was used for the assessment of differences between the analysed variables. Results at a level of $\mathrm{p}<0.05$ were considered statistically significant.

The data used in the analysis covered 518 cycles of in vitro fertilization. The following variables were chosen: female age, the number and quality of oocytes retrieved during stimulation ( $G V, M 1, M 2$ (after IR, at ICSI), $M 2^{*}$ - stages of maturity - presented as percentages), the number and quality of the produced embryos ( $2 P N, N E F 2 P B, 1, \geq 3 P N$, clvd on day 3 , $\geq 7$ cell on day 3 , blasts on day 5 , blasts on day 6 - presented as percentages), the number of transferred embryos (ET number), the day of transfer (ET), and information about pregnancy and miscarriage. Pregnancy was determined on the basis of a pregnancy test (biochemical pregnancy) and then confirmed in an ultrasound examination by observing the heartbeat (clinical pregnancy). Miscarriages were the cases in which pregnancy was determined only biochemically, unconfirmed during the ultrasound examination. In the tested group, pregnancy could not be achieved in $54 \%$ of women $(n=281), 10 \%$ of women $(n=51)$ miscarried, whereas $36 \%$ of women $(n=186)$ achieved pregnancy confirmed in the ultrasound examination. Non-pregnancy was set as the reference category in multinomial logistic regression models.

An analysis of the differences between pregnancy, non-pregnancy, and miscarriage showed 10 features that are statistically different in the groups in question. The differences between pregnancy and non-pregnancy con- 
cerned female age, follicles $(n)$, retrieved oocytes $(n)$, fertilized oocytes $(n)$, at least 7-cell embryos on day $3(\%)$, blasts on day $5(\%)$ and day $6(\%)$, and day of transfer. Differences between miscarriage and non-pregnancy were present for 5 variables: female age, follicle $(n)$, M2 after ER (\%), M2 at ICSI (\%), and for at least 7-cell embryos on day $3(\%)$. Differences between miscarriage and non-pregnancy were present for 2 variables only: blasts on day $5(\%)$ and day $6(\%)$ (Table 1$)$.

Table 1. Differences between patients with non-pregnancy, miscarriage, and pregnancy. Comparisons vs. non-pregnancy: $\mathbf{p}<0.05^{*}, \mathrm{p}<0.01 * *$, $\mathbf{p}<0.001 * * *$, comparisons vs. pregnancy: $\mathbf{p}<0.05 \#, \mathbf{p}<0.01$ \#\#, $\mathrm{p}<0.001$ \#\#\#. Results presented as median, and upper and lower quartile

\begin{tabular}{|l|c|c|c|}
\hline \multicolumn{1}{|c|}{ Variables } & $\begin{array}{c}\text { Non-pregnancy } \\
(n=281,54.25 \%)\end{array}$ & $\begin{array}{c}\text { Miscarriage } \\
(n=51,9.85 \%)\end{array}$ & $\begin{array}{c}\text { Pregnancy } \\
(n=186,35.91 \%)\end{array}$ \\
\hline female age (years) & $40.0(36.0-42.0)$ & $36.0(31.0-40.0)^{* *}$ & $36.0(33.0-40.0)^{* * *}$ \\
\hline follicles $(\mathrm{n})$ & $10.0(7.0-16.0)$ & $14.0(11.0-18.0)^{*}$ & $15.0(12.0-20.0)^{* * *}$ \\
\hline retrieved oocytes $(\mathrm{n})$ & $8.0(4.0-14.0)$ & $11.0(6.0-16.0)$ & $12.0(9.0-21.0)^{* * *}$ \\
\hline M2 after ER $(\%)$ & $0.7(0.5-0.8)$ & $0.7(0.4-0.8)^{*}$ & $0.7(0.6-0.9)$ \\
\hline M2 at ICSI $(\%)$ & $0.7(0.5-0.8)$ & $0.7(0.4-0.8)^{*}$ & $0.7(0.6-0.9)$ \\
\hline fertilized oocytes $(\mathrm{n})$ & $6.0(3.0-11.0)$ & $7.0(5.0-13.0) \#$ & $10.0(7.0-16.0)^{* * *}$ \\
\hline$\geq 7$ cell on day 3 $(\%)$ & $0.4(0.2-0.5)$ & $0.5(0.3-0.7)^{*}$ & $0.5(0.3-0.6)^{* * *}$ \\
\hline blasts on day 5 (\%) & $0.0(0.0-0.05)$ & $0.0(0.0-0.25) \#$ & $0.1(0.0-0.28)^{* * *}$ \\
\hline blasts on day 6 $(\%)$ & $0.0(0.0-0.11)$ & $0.0(0.0-0.17) \#$ & $0.1(0.0-0.29)^{* * *}$ \\
\hline ET (day) & $3.0(3.0-3.0)$ & $3.0(3.0-5.0)$ & $3.00(3.0-5.0)^{* * *}$ \\
\hline
\end{tabular}

As female age has the greatest impact on treatment outcome (Milewski et al., 2008), it appears in all the created models. The first multinomial logistic regression model was built on the basis of data concerning the quality and number of retrieved oocytes and female age only (Table 2). The variables that turned out to be significant in the model are the number of follicles, the percentage of mature oocytes (M2 after ER), and female age.

The obtained model (Table 2) enables to conclude that as female age increases by a year, the relative risk of miscarriage (vs. non-pregnancy) decreases by $9 \%$, whereas the relative risk of pregnancy (vs. non-pregnancy) decreases by $8 \%$, at the other parameters set. However, if the number of oocytes in the ovary increases by 1 , then the relative risk of pregnancy (vs. non-pregnancy) increases by $7 \%$, at the other parameters set. In the 
Table 2. The first multinomial logistic regression model built on the basis of information about retrieved oocytes and female age (Model I)

\begin{tabular}{|c|c|c|c|c|c|c|c|}
\hline outcome & I & RRR & Std. Err. & $\mathrm{z}$ & $\mathrm{P}>|\mathrm{z}|$ & [95용 Conf. & Interval] \\
\hline 0 & 1 & \multicolumn{6}{|c|}{ (base outcome) } \\
\hline 1 & I & & & & & & \\
\hline $\begin{array}{r}\text { female age } \\
\text { follicles }\end{array}$ & i & $\begin{array}{l}.9098818 \\
1.021295\end{array}$ & $\begin{array}{l}.0320923 \\
.0268963\end{array}$ & $\begin{array}{r}-2.68 \\
0.80\end{array}$ & $\begin{array}{l}0.007 \\
0.424\end{array}$ & $\begin{array}{l}.8491068 \\
.9699166\end{array}$ & $\begin{array}{r}.9750067 \\
1.075395\end{array}$ \\
\hline $\begin{array}{r}\text { M2afterERs } \\
\text { Cons }\end{array}$ & i & $\begin{array}{l}.8827874 \\
5.120301\end{array}$ & $\begin{array}{r}.5781835 \\
7.982939\end{array}$ & $\begin{array}{r}-0.19 \\
1.05\end{array}$ & $\begin{array}{l}0.849 \\
0.295\end{array}$ & $\begin{array}{l}.2445456 \\
.2411056\end{array}$ & $\begin{array}{l}3.186782 \\
108.7386\end{array}$ \\
\hline 2 & i & & & & & & \\
\hline $\begin{array}{r}\text { female age } \\
\text { follicles }\end{array}$ & i & $\begin{array}{l}.9231549 \\
1.067369\end{array}$ & $\begin{array}{l}.0215999 \\
.0183339\end{array}$ & $\begin{array}{r}-3.42 \\
3.80\end{array}$ & $\begin{array}{l}0.001 \\
0.000\end{array}$ & $\begin{array}{r}.881776 \\
1.032034\end{array}$ & $\begin{array}{l}.9664755 \\
1.103915\end{array}$ \\
\hline $\begin{array}{r}\text { LM2afterERs } \\
\text { _cons }\end{array}$ & 1 & $\begin{array}{r}3.04194 \\
2.464636\end{array}$ & $\begin{array}{r}1.38779 \\
2.603459\end{array}$ & $\begin{array}{l}2.44 \\
0.85\end{array}$ & $\begin{array}{l}0.015 \\
0.393\end{array}$ & $\begin{array}{l}1.243989 \\
.3108898\end{array}$ & $\begin{array}{l}7.438487 \\
19.53886\end{array}$ \\
\hline
\end{tabular}

case of miscarriage, the number of oocytes was not statistically significant. Moreover, if the number of M2 oocytes is greater by $1 \%$ then the relative risk of pregnancy (vs. non-pregnancy) increases by 1\%; at an increase of the percentage of oocytes by $10 \%$ the relative risk of pregnancy is greater by $11 \%$, at the other parameters set. In the case of miscarriage, the percentage of M2 oocytes has no significant impact.

The second multinomial regression model was built on the basis of data describing the quality and number of the produced embryos, data concerning transfer and female age (Table 3). In this model, the following variables turned out to be statistically significant: female age, at least 7-cell embryos on day $3(\%)$, blasts on day $5(\%)$ and day of transfer.

Table 3. The multinomial regression model built on the basis of information about the produced embryos and female age (Model II)

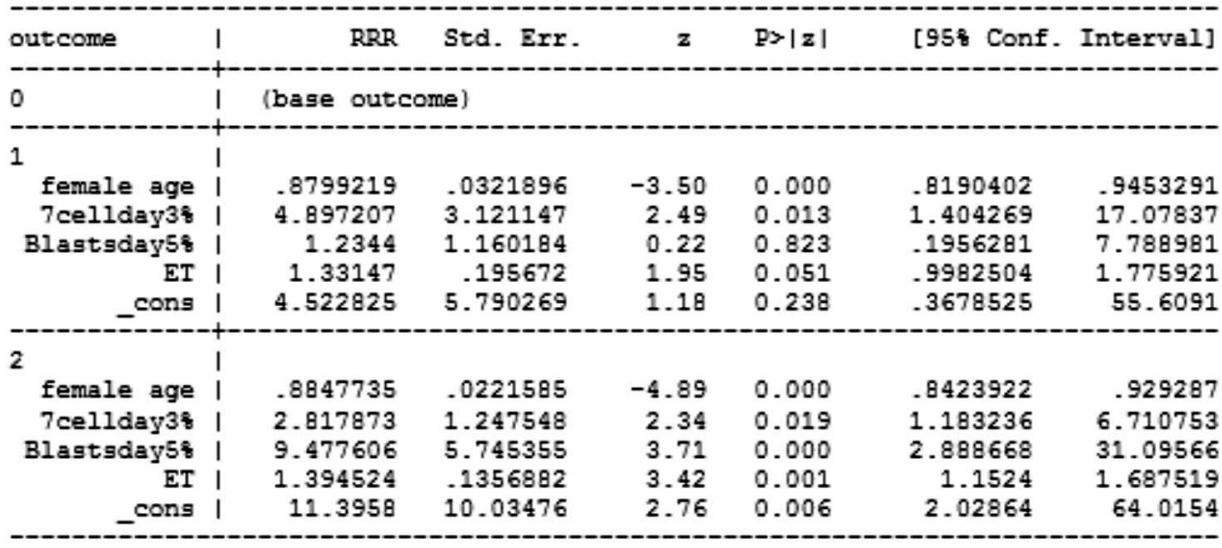

0 - non-pregnancy, 1 - miscarriage, 2 - pregnancy 
When interpreting this model (Table 3) it can be concluded that if female age increases by 1 year, then the relative risk of miscarriage (vs. nonpregnancy) as well as the relative risk of pregnancy (vs. non-pregnancy) decreases by $12 \%$, at the other parameters set. If the percentage of at least 7 -cell embryos on day 3 increases by $1 \%$, then the relative risk of miscarriage (vs. non-pregnancy) increases by almost $2 \%$; at an increase of the percentage of embryos by $10 \%$, the relative risk of miscarriage increases by $17 \%$. On the other hand, if the percentage of at least 7-cell embryos on day 3 is greater by $1 \%$ then the relative risk of pregnancy (vs. non-pregnancy) increases by $1 \%$; at an increase of the percentage of embryos by $10 \%$, the relative risk of pregnancy increases by $11 \%$ (at the other parameters set). At an increase of the percentage of blastocysts on day 5 by $1 \%$, the relative risk of pregnancy (vs. non-pregnancy) increases by $2 \%$; at an increase of the percentage of blastocysts by $10 \%$, the relative risk of pregnancy increases by $22 \%$, at the other parameters set. The percentage of blastocysts, however, does not have a statistically significant impact on miscarriage. If transfer of embryos is postponed by 1 day, then the relative risk of miscarriage (vs. non-pregnancy) increases 1.3 times, while the relative risk of pregnancy (vs. non-pregnancy) increases 1.4 times (at the other parameters set).

The third multinomial regression model was to be built on the basis of all the available data, i.e. describing both the quality and the number of retrieved oocytes, and concerning the number and quality of embryos, the day of transfer, and female age. Unfortunately, this model reduced into model II, which is why it is not presented for the second time in this paper.

\section{Conclusions}

Multinomial regression models have a wide range of applications in medicine. As they enable to assess the relative risk for a multi-state dependent variable, the models are more universal than typical logistic regression. The models presented in this paper are used for predicting infertility treatment outcomes (pregnancy, miscarriage, non-pregnancy). As female age has the greatest impact on treatment results, it is present in all the obtained models. The first of the multi-factor models enabled to conclude that if treatment outcomes are to be predicted on the basis of information about oocytes, then the number of follicles and the percentage of retrieved mature oocytes have a significant impact. The second of the multi-factor models, built on the basis of information about embryos, showed the number of 
fertilized oocytes, the percentage of at least 7-cell embryos on day 3 , the percentage of blasts on day 5, and the day of transfer as significant. An attempt to build a model on the basis of all available variables was unsuccessful, as the model reduced to the variables describing the quality of embryos only.

\section{R E F E R E N C E S}

Agresti, A. (2002). Categorical Data Analysis (2nd ed.). New York, NY, USA: Wiley-Interscience.

Al-balushi, M. S., Ahmed, M. S., Mazharul Islam, M., \& Khan, M. H. R. (2016). Contraceptive Method Choices Among Women In Oman: A Multilevel Analysis. Journal of Data Science, 14, 117-132.

Atkinson, R. L., El-Zein, R., Valero, V., Lucci, A., Bevers, T. B., Fouad, T., Liao, W., et al. (2016). Epidemiological Risk Factors Associated with Inflammatory Breast Cancer Subtypes. Cancer Causes \& Control, 27(3), 359-366.

Can, V. V. (2013). Estimation of travel mode choice for domestic tourists to Nha Trang using the multinomial probit model. Transportation Research Part A: Policy and Practice, 49, 149-159.

Cleynen, I., Boucher, G., Jostins, L., Schumm, L. P., Zeissig, S., Ahmad, T., Andersen, V., et al. (2016). Inherited determinants of Crohn's disease and ulcerative colitis phenotypes: A genetic association study. The Lancet, 387(10014), 156-167.

Dolansky, M. A., Xu, F., Zullo, M., Shishehbor, M., Moore, S. M, \& Rimm, A. A. (2010). Post-acute care services received by older adults following a cardiac event: a population-based analysis. Journal of Cardiovascular Nursing, 25(4), 342-349.

El-Habil, A. M. (2012). An Application on Multinomial Logistic Regression Model. Pakistan Journal of Statistics and Operation Research, 8(2), 271-291.

Hosmer, D. W., \& Lemeshow, S. (2000). Applied logistic regression. New York: Wiley.

Kohansal, M. R., \& Firoozzare, A. (2013). Applying Multinomial Logit Model for Determining Socio-Economic Factors Affecting Major Choice of Consumers in Food Purchasing: The Case of Mashhad. Journal of Agricultural Science and Technology, 15, 1307-1317.

Medina-Solis, C. E., Maupone, G., del Socorro, H. M., Perez-Nunez, R., AvilaBurgos, L., \& Lamadrid-Figueroa, H. (2008). Dental Health Services Utilization and Associated Factors in Children 6 to 12 Years Old in a Low-Income Country. Journal of Public Health Dentistry, 68(1), 39-45. 
Milewska, A. J., Jankowska, D., Citko, D., Więsak, T., Acacio, B., \& Milewski, R. (2014). The use of principal component analysis and logistic regression in prediction of infertility treatment outcome. Studies in Logic, Grammar and Rhetoric. Logical, Statistical and Computer Methods in Medicine, 39(52), $7-23$.

Milewska, A. J., Jankowska, D., Cwalina, U., Citko, D., Więsak, T., Acacio, B., \& Milewski, R. (2016). Prediction of infertility treatment outcomes using classification trees. Studies in Logic, Grammar and Rhetoric. Logical, Statistical and Computer Methods in Medicine, 47(60), 7-19.

Milewska, A. J., Górska, U., Jankowska, D., Milewski, R., \& Wołczyński, S. (2011). The use of the basket analysis in a research of the process of hospitalization in the gynecological ward. Studies in Logic, Grammar and Rhetoric. Logical, Statistical and Computer Methods in Medicine, 25(38), 83-98.

Milewski, R., Jankowska, D., Cwalina, U., Milewska, A. J., Citko, D., Więsak, T., Morgan, A., \& Wołczyński, S. (2016). Application of artificial neural networks and principal component analysis to predict results of infertility treatment using the IVF method. Studies in Logic, Grammar and Rhetoric. Logical, Statistical and Computer Methods in Medicine, 47(60), 33-46.

Milewski, R., Milewska, A. J., Czerniecki, J., Leśniewska, M., \& Wołczyński, S. (2013). Analysis of the demographic profile of patients treated for infertility using assisted reproductive techniques in 2005-2010. Ginekologia Polska, 84(7), 609-614.

Milewski, R., Milewska, A. J., Domitrz, J., \& Wołczyński, S. (2008). In vitro fertilization ICSI/ET in women over 40. Przeglad Menopauzalny, 7(2), 85-90.

Miyamoto, M. (2014). Credit Risk Assessment for a Small Bank by Using a Multinomial Logistic Regression Model. International Journal of Finance and Accounting, 3(5), 327-334.

Mukesi, M., Phillipus, I. N., Moyo, S. R., \& Mtambo O. P. L. (2017). Prevalence of Skin Allergies in Adolescents in Namibia. International Journal of Allergy Medications, 3(1):022.

Neupane, B., McDonald, S. D., \& Beyene, J. (2015). Identifying determinants and estimating the risk of inadequate and excess gestational weight gain using a multinomial logistic regression model. Open Access Medical Statistics, 5, $1-10$.

Okasha, M. K., \& Abu-Saada, A. H. K. (2014). Modeling Violence against Women in Palestinian Society. American International Journal of Contemporary Research, 4(1), 209-220.

Pesatori, A. C., Carugno, M., Consonni, D., Hung, R. J., Papadoupolos, A., Landi, M. T., Brenner, H., et al. (2013). Hormone use and risk for lung cancer: a pooled analysis from the International Lung Cancer Consortium (ILCCO). British Journal of Cancer, 109, 1954-1964.

Radwan, J., \& Wołczyński, S. (Eds.). (2011). Niepłodność i rozród wspomagany. Poznań, Polska: Termedia Wydawnictwa Medyczne. 
Ranciere, F., Nikasinovic, L., \& Momas, I. (2013). Dry night cough as a marker of allergy in preschool children: the PARIS birth cohort. Pediatric Allergy and Immunology, 24(2), 131-137.

Sadat-Hashemi, S. M., Kazemnejad, A., Lucas, C., \& Badie, K. (2005). Predicting the type of pregnancy using artificial neural networks and multinomial logistic regression: a comparison study. Neural Computing \& Applications, 14(3), 198-202.

Tabatabai, M. A., Li, H., Eby, W. M., Kengwoung-Keumo, J. J., Manne, U., Bae, S., Fouad, M., \& Singh, K. P. (2014). Robust Logistic and Probit Methods for Binary and Multinomial Regression. Journal of Biometrics and Biostatistics, 5(4): 202.

Van Deventer, D. R., Imai, K., \& Mesler, M. (2013). Advanced Financial Risk Management. Tools and Techniques for Integrated Credit Risk and Interest Rate Risk Management. Singapore: John Wiley \& Sons.

Yildirim, G. Y., Turkgeldi, L. S., Koroglu, N., Guler, S., \& Talmac, M. A. (2017). Predictive factors for pregnancy outcome following controlled ovarian stimulation and intrauterine insemination. Journal of Pakistan Medical Association, 67(3), 422-427. 